\title{
Surface Characteristics of Cotton/ Polyester Fabric Coated with Poly-urethane Elastomers Cured Thermally or by Using Gamma Irradiation
}

\section{H. M. Eyssa and M. S. Hassan}

Radiation Chemistry Dept., National Centre for Radiation Research and Technology (NCRRT), P. O .Box; 29 Nasr City, Egypt.

\footnotetext{
IFFERENT POLYURETHANE (PU) elastomerics formulations were prepared by using 4, 4'-diphenyl methane diisocyanate, polyol (castor oil; $\mathrm{CO}$ ), chain extender (1,4-butanediol); CE and catalyst. The prepared PU formulations were applied as coating films up on the cotton/ polyester blend fabric surface. The specimens were cured to complete the reaction of the PU spell, either thermally $\left(140^{\circ} \mathrm{C}\right)$ or by using $\gamma$-rays at different doses $(30-150 \mathrm{kGy})$. The PU layer formed up on the fabric surface was characterized by using Fouriertransform infrared (FTIR). The effects of CE percent and the used curing system on the coated fabrics properties, such as mechanical properties, thermal stability, water absorbance, crease recovery and surface morphology were investigated. The results showed that the increasing of CE percent and the irradiation dose lead to improving the tensile strength; $\mathrm{MPa}$ and the thermal stability, while, the elongation at break (\%), crease recovery and water absorbance were decreased.

Keywords: Cotton/ polyester fabric, polyurethane, chain extender, water absorbance.
}

Polymer-coated textiles are flexible composite materials comprising the coat the polymer and the substrate textile adhered together through a specific coating process to provide additional properties for the textiles. Different applications can be obtained through the coating processes of textile such as: military tent, protective clothing for firemen, waterproof jackets, and seat upholstery for cars. In certain special applications, the coating processes can also help to provide water repellent property (Minghua et al., 2007), flame retardant shielding (Saad et al., 2005 and Stephane et al., 2005), colouring of the fabrics with pigment colours (Elnaggar et al., 2005), improving the water vapour permeability (Jong et al., 2007), antimicrobial properties oil and soil repellence (Boris et al., 2005). The physical textile properties such as: strength (tear and tensile), 
elongation, dimensional properties and fabric abrasion were improve via the coating processes. The PUs are a spell class of polymers, because they have a wide range of applications due to their properties which can be spell by the variation of their compositions (Oprea et al., 2000). The urethane linkage is formed by the reaction of an isocyanate group of one reactant with the alcohol group of another component. The micro-structure of a PU block itself is generally known to be composed of different phases, i.e., it is based on domains which have been built of hard urethane type segments derived from diisocyanates and CE connected with soft domains which have been built from flexible segments derived from polyol components (Barikani et al., 2008). This flexibility has led PU to find use as synthetic polymers in foams, elastomers, coatings, sealants, medical and adhesive based products. Some of the applications of PU lie in the textile finishing, automotive, furniture, construction, and thermal insulation and footwear industries (Zia et al., 2007).

There are only a limited number of reports about the preparation and application of eco-friendly binder for textile finishing purposes. Great efforts have been spell of PU to increase the spell of the coatings (Wang et al., 2008). In this way, extensive possibilities are offered to obtain the polymer structure which will be spell for particular spell (K'rol et al., 2005). PU coatings are used in textile industry as finishing agents to improve the durability, improve the water vapour permeability of coated fabrics and encapsulation of different additives for different applications (Jong et al., 2007).

In the present study, the cotton/ Polyester blend fabrics were coated with different PU formulations prepared by the reaction of 4, 4'-diphenyl methane diisocyanate (MDI), different ratios of (CO, 1, 4-butanediol) and catalyst. A systematic study of the effect gamma irradiation and thermal curing on the structural characterization and thermo-mechanical properties of cotton fabric coating with PU has been provided.

\section{Experimental}

\section{Chemicals}

The chemicals used in this study for the preparation of polymer are: MDI, $\mathrm{CO}$ (molecular wt $=930$, hydroxyl functionality $=2$, supplier (Gomaherai for chemical industries, Cairo, Egypt), 1,4-butanediol (BD) (molecular $\mathrm{wt}=90$,

Egypt. J. Rad. Sci. Applic., Vol. 27, No. 1-2 (2014) 
Specification Assay (GC) area\% $\geq 99 \%$, density $\left(\mathrm{d} 20 \% / 4^{\circ} \mathrm{C}\right)=1.015-1.016$, water (K.F) $\leq 0.3 \%$, Merck Schuchardt OHG Hohenbrunn, Germany). CO and BD used in this study are dried at $80^{\circ} \mathrm{C}$ in vacuum for $24 \mathrm{~h}$ before use to ensure the removal of all air bubbles and water vapours that may otherwise interfere with the isocyanate reactions. Cobalt naphthenate (Fluka, Buchs, Switzerland) used as reaction catalyst. Cotton/polyester plain weave blend fabric $\left(215 \mathrm{~g} / \mathrm{m}^{2}\right)$ 30:70, were kindly supplied by Egyptian Company for Textile, El-Mahalla, Egypt, were used after washing and scouring.

\section{Preparation of PU elastomerics}

The PU was easily prepared by one shot polymerization method in scheme 1 , in which, the required wt of $\mathrm{CO}, \mathrm{BD}$ and catalyst $(0.088 \mathrm{~g})$ are stirred spell for 6 min, then MDI is added and the mixture stirred for a few seconds.

Different formulations were prepared according to the $\mathrm{CO} / \mathrm{BD}$ ratio as shown in Scheme 1.

$$
\underset{\text { Diisocyanate }}{2 \mathrm{OCN}-\mathrm{R}_{1}-\mathrm{NCO}}+\underset{\text { Polyol }}{\mathrm{HO}} \underset{\text { Chen extender }}{(\mathrm{R})_{n}} \mathrm{OH}+\underset{\text { Chain enter }}{\mathrm{HO}-\left(\mathrm{CH}_{2}\right)_{4}} \mathrm{OH}
$$

$$
\text { One shot }
$$

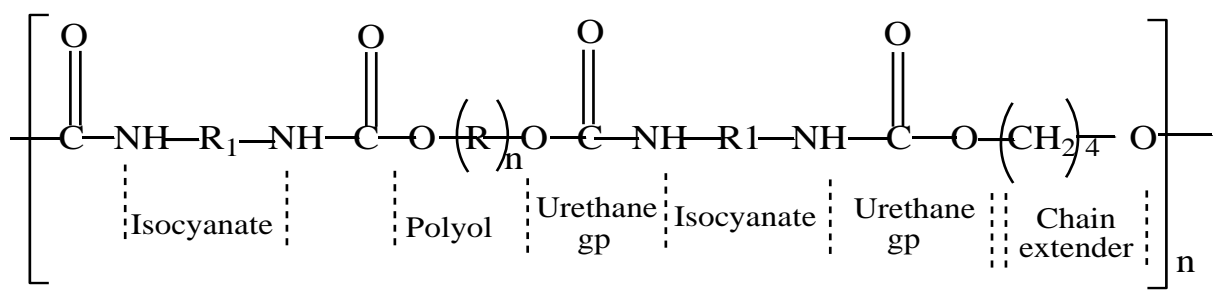

Scheme 1. One shot reaction for PU elastomerics preparation.

Where,<smiles></smiles>

Egypt. J. Rad. Sci. Applic., Vol. 27, No. 1-2 (2014) 


\section{Coating of the fabrics with PU elastomerics}

After the preparation of PU containing various ratios CO/CE, i.e., 70/30, $60 / 40,50 / 50$ and 40/60 are applied on the fabric surface by using film applicator. The coated cotton/PET fabrics were dried at $50^{\circ} \mathrm{C}$ for $30 \mathrm{~min}$, then they exposure to curing process, either thermally $\left(140^{\circ} \mathrm{C}\right.$ for $\left.5 \mathrm{~min}\right)$ or by using different doses of gamma irradiation. All the coated samples were washed in distilled water at boiling temperature, for $30 \mathrm{~min}$ to extract the unreacted PU ingredients.

TABLE . The compositions of prepared PU elastomerics formulations.

\begin{tabular}{|c|c|c|c|c|c|c|}
\hline \multirow{2}{*}{ Formulation } & CO/ CE & \multicolumn{2}{|c|}{ PU ingredients wt (g) } & Iscyanate/ OH & Catalyst wt \\
\cline { 3 - 5 } & ratios (\%) & CO & BD & MDI & ratio & $(\mathrm{g})$ \\
\hline PU 1 & $70: 30$ & 32.55 & 1.35 & 12.5 & $1: 1$ & 0.088 \\
\hline PU 2 & $60: 40$ & 27.90 & 1.8 & 12.5 & $1: 1$ & 0.088 \\
\hline PU 3 & $50: 50$ & 23.25 & 2.25 & 12.5 & $1: 1$ & 0.088 \\
\hline PU 4 & $40: 60$ & 18.6 & 2.7 & 12.5 & $1: 1$ & 0.088 \\
\hline
\end{tabular}

\section{Gamma-radiation}

Irradiation was carried out in the Cobalt-60 gamma cell source (made in Russia) installed at NCRRT, Cairo, Egypt. The direct radiation was used for induced the curing process of coated cotton/polyester blend fabrics.

\section{Characterization of coated cotton/ PET blend fabrics with PU}

The coating PU film upon the cotton/ PET blend fabric surface was extracted by using DMF solvent at boiling for $10 \mathrm{~min}$, then it analyzed by FTIR, in a wide range wavelength between $400 \mathrm{~cm}^{-1}$ and $4000 \mathrm{~cm}^{-1}$, and in solid state using Mattson 5000 FTIR spectrometer (Mattson Instruments, Madison). The mechanical properties including Tensile strength; MPa and elongation to break were tested at room temperature. Every data point is the average of 5 tests (Mecmesin tester, Mecmesin Limited, UK). Spell with software was used employing a crosshead speed of $50 \mathrm{~mm} / \mathrm{min}$. In this system the different mechanical parameters were calculated directly.

The SEM study of coated blend fabrics were carried out by JEOL JSM$640 \mathrm{SEM}$, at 20MA and $15 \mathrm{kV}$. The dried fabric samples were cut and sputtercoated with a thin film of gold using a microscope sputter coater and viewed through the microscope. Thermogravimetric analysis (TGA) was determined by using Shmadzu-30 (TGA-30) at a heating rate of $10^{\circ} \mathrm{C} / \mathrm{min}$ in air over a temperature range from room temperature up to $600^{\circ} \mathrm{C}$.

Egypt. J. Rad. Sci. Applic., Vol. 27, No. 1-2 (2014) 


\section{Water absorbance}

The water absorbance properties of coated cotton/ PET fabrics with PU were evaluated by using static absorption test according to the American Association of Textile Chemists and Colourists (AATCC) test method 21-1972. In this test, a sinker is fastened to one side of a conditioned definite wt of test sample $\left(\mathrm{W}_{\mathrm{o}}\right)$, to sink it to the bottom of the immersion tank containing distilled water for $30 \mathrm{~min}$ and then the sample is removed from the sinker and quickly placed between two pieces of dry blotting paper to remove residual water on the surface. The sample is reweighed quickly (W), and the percentage of water absorption is calculated according to the following equation (1):

$$
\text { Water absorption }\left(\%=\left\{\left(W-W_{0}\right) / W_{0}\right\} \times 100\right.
$$

\section{Crease recovery}

In principle, the ability of the fabric to resist and recover the deformation after releasing any load to the initial wrinkle free surface is expressed as crease recovery properties. The crease recovery of the fabric is measured by the angle between the pre- folded halves and is termed as the crease recovery angle. The crease recovery properties were determined in the dry and wet states of the fabrics, according to the ASTMD-1295-67 using a cease recovery tester model (METEFEM- Metrinpex) type FF-07, made by Hungary. The used load was 1 $\mathrm{kg}$ for $5 \mathrm{~min}$ at room temperature. The tested samples were cut according to a special standard rectangular shape. The recorded value of crease recovery angle is the average of five measurements.

\section{Results and Discussion}

\section{FTIR}

FTIR spectra of cotton/ PET blend fabrics coated with PU is shown in Fig. 1, the change of transmittance in the FTIR spectra recorded for PU formulation before and after curing either thermally or by irradiation was shown in Fig. 1, where the Infra red (IR) spectra of non cured PU Fig. 1(a), thermally cured PU Fig. 1(b), gamma irradiated at $30 \mathrm{kGy}$ Fig. 1(c) and gamma irradiated at 150 kGy Fig. 1(d) are represented. It can be seen the characteristic adsorption peaks of the urethane groups, which appear at $1702-1733 \mathrm{~cm}^{-1}$ representing the $\mathrm{C}=\mathrm{O}$ groups stretching of soft segment of $\mathrm{CO}, 3390 \mathrm{~cm}^{-1}$ representing the N-H group, 
$1530 \mathrm{~cm}^{-1}$ representing the hydrogen bonded urethane carbonyl group, 2860$2933 \mathrm{~cm}^{-1}$ representing $\mathrm{CH}$ symmetric stretching of $\mathrm{CH}_{2}, 1240 \mathrm{~cm}^{-1}$ represents the asymmetric C-O-C stretching, and at $1085-1115 \mathrm{~cm}^{-1}$ representing the ester segment of PU. As shown in Fig. 1(b), the characteristic absorption beaks intensities of the PU was not greatly changed after thermally curing, but by using the irradiation curing, it can be notice a decreasing in the carbonyl group intensity at $1733 \mathrm{~cm}^{-1}$, companied with a decreasing in the range of 1085-1115 $\mathrm{cm}-1$, which indicate the degradation of the ester segment and their oxidation to hydroxyl groups in the structure of PU as a result of the irradiation process. The decrease of intensity of the characteristic PU bands with the increasing of the irradiation dose could be attributed to the presence of some oxidative radical process as shown in Fig. 1(c\&d) (Chapiro1995 and Wilhelm et al., 1998).

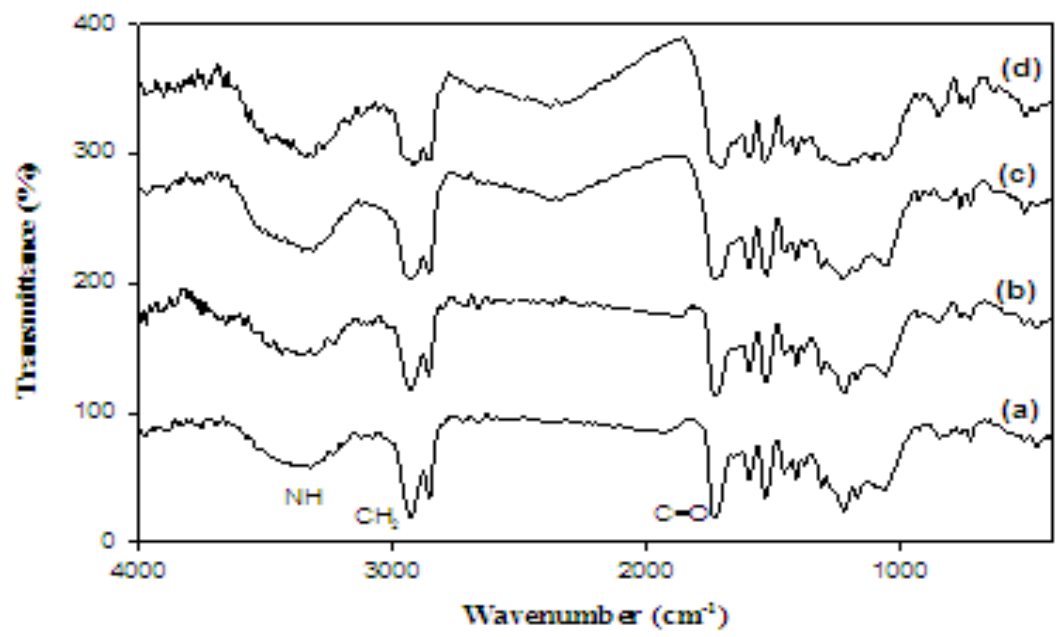

Fig. 1. FTIR spectra of: (a) uncured $\mathrm{PU}$, (b) thermally cured $\mathrm{PU}\left(140^{\circ} \mathrm{C}\right)$, (c) irradiation cured PU at $30 \mathrm{kGy}$ and (d) irradiation cured PU at $150 \mathrm{kGy}$.

\section{Mechanical properties}

The change in the tensile straight; MPa and elongation percent at break for cotton/ PET blend fabrics coated with different PU formulations under the different curing systems (thermally or by using gamma irradiation doses) are shown in Fig. 2\&3. It can be seen that, in general, the tensile straight; MPa was improved after coating with PU formulations by using the both of curing systems, which enhances the copolymerization of PU ingredients. By comparing between the 2 curing systems, it was found that the tensile straight; MPa gave higher

Egypt. J. Rad. Sci. Applic., Vol. 27, No. 1-2 (2014) 
values after curing by using $\gamma$-rays, increasing by increasing the irradiation dose up to $150 \mathrm{kGy}$. It was found also that, the tensile straight; MPa were affected sharply according to the CE percent in the different PU formulations, in which, the increasing in the CE percent, leads to increase the tensile strength; MPa of coated fabrics. This could be attributed to the increasing of the hard segment content for $\mathrm{CE} /$ polyol ratio and the increasing of $\mathrm{H}$-bonding density in PU bonds (Zia et al., 2009).

From Fig. 3, it can be seen that the elongation at break (\%) was affected by the curing systems and by the CE percent in the PU formulations, in which, it decreases by increasing the irradiation dose as a result of the increasing in the cross linking density of PU. Also, it decreases by increasing the CE percent, due to the increasing of the hard segment content and the hydrogen bonds formed.

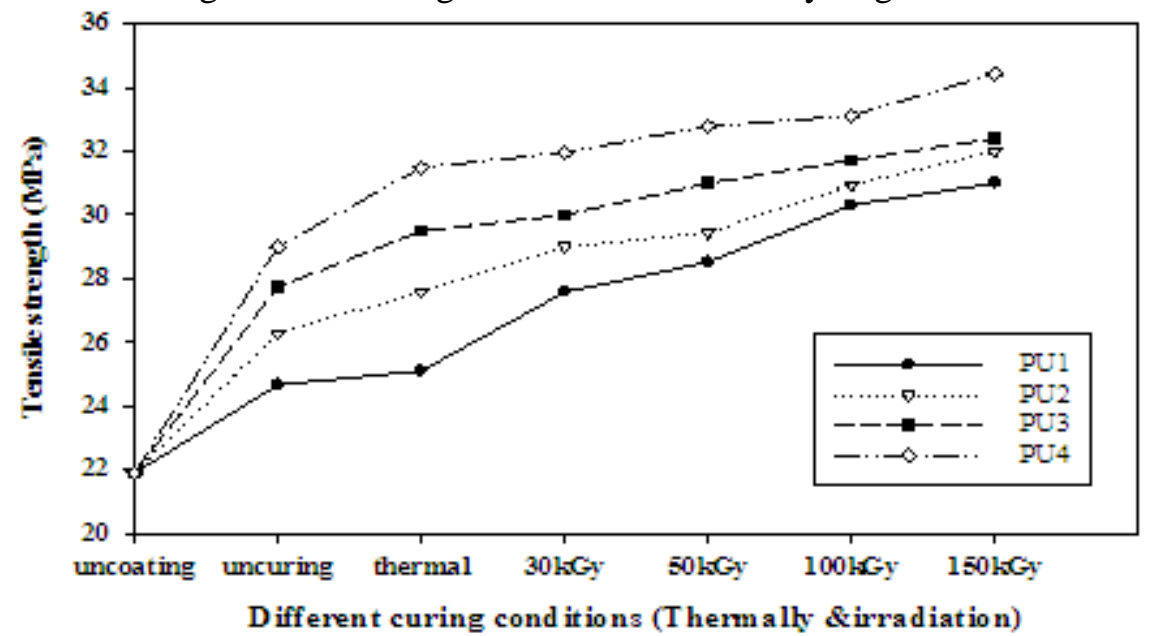

Fig. 2. The tensile strength at break of uncoated and coated cotton/ PET fabrics with different $P U$ formulations cured either thermally or with $\gamma$-rays.

\section{Water absorbance}

The water absorbance of cotton/ PET blend fabrics coated with different PU-formulations under the different curing systems (thermally or by using $\gamma$-rays doses) is shown in Fig. 4. It was found that, in general, the water absorbance, which represents the hydrophylicity of the fabrics decreases after coating with PU-formulation, but it varying according to the used curing system, in which, it decreases in the case of irradiation curing less than it after 
thermal curing. This could be attributed to the increasing of the cross linking density of polymerized PU-formulations, which cover more microspores sites of the fabric surface. By increasing of the irradiation dose up to $150 \mathrm{kGy}$, the water absorbance decreases gradually with increasing the cross linking of the PU by $\gamma$ rays. The increasing in the $\mathrm{CE}$ percent in the different PU formulations leads to decrease the water absorbance of coated fabrics, due to the increasing in the cross linking density and due to the hydrophopicity nature of CE (Oprea, 2010). So, with increasing of CE-content, the cross link density increases and the polymer structure becomes more rigid, dense and the possibility of water molecules to penetrate the fabric PU decreases.

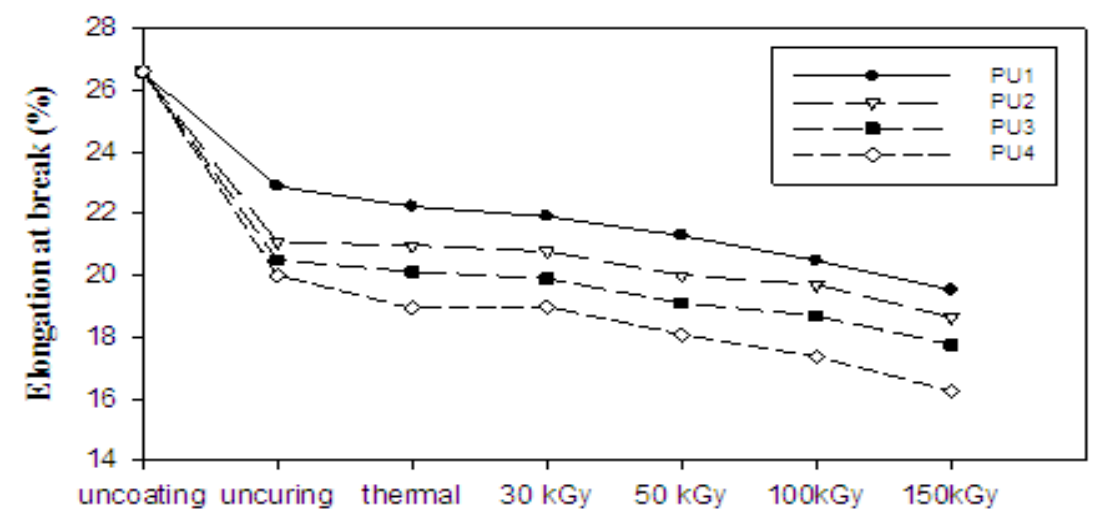

Different curing conditions (thermally \& irradiation)

Fig. 3. The elongation (\%) at break of uncoated and coated cotton/ PET fabric with different PU formulations cured either thermally or with $\gamma$-rays.

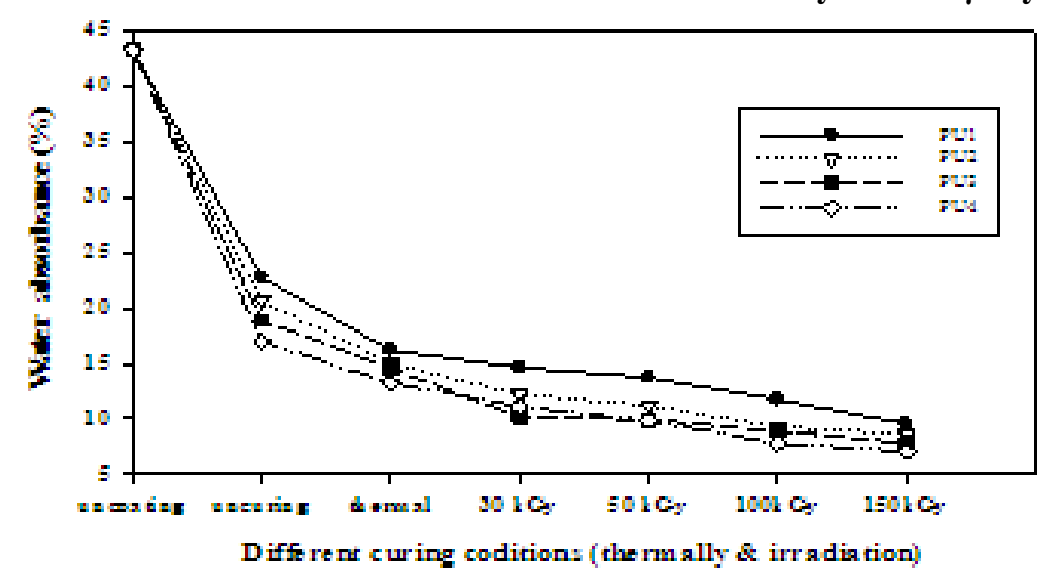

Fig. 4. The water absorbance (\%) of uncoated and coated cotton/ PET fabrics with different PU formulations cured either thermally or with $\gamma$-rays.

Egypt. J. Rad. Sci. Applic., Vol. 27, No. 1-2 (2014) 


\section{Crease recovery}

Table 2. shows the crease recovery properties of cotton/ PET blend fabrics coated with different PU formulations under the different curing system (thermally or by using gamma irradiation doses). It can be seen, in general, that the crease recovery angle of the fabrics decreases after coating with PU formulation, but it varying according to the used curing system, in which, it decreases in the case of irradiation curing less than it after thermal curing. The crease recovery angle was decreased with increasing of the irradiation dose up to $150 \mathrm{kGy}$. It could be attributed to the increasing in the cross linking density of polymerized PU, which accompanied by increasing in the rigidity and decreasing in the flexibility of coated fabrics. The increasing of CE percent in the PU formulations leads to decrease the crease recovery angle as a result of the increasing of the cross linking density, increasing in the hydrogen bond formed, which make the coated fabrics with PU film more rigid and tougher, resist returning to their initial shape. The same trend was obtained either with the dry fabric state or with the wet fabric state, but with higher values in the wet state, in which, the coated fabric flexibility increases.

TABLE 2. The crease recovery properties of coated cotton/ PET fabrics with different PU formulation under different curing conditions.

\begin{tabular}{|c|c|c|c|c|c|c|c|c|}
\hline \multirow{2}{*}{ Curing conditions } & \multicolumn{9}{|c|}{ Crease recovery angle $\left(^{\circ}\right)$} \\
\cline { 2 - 10 } & \multicolumn{2}{|c|}{ PU 1 } & \multicolumn{2}{c|}{ PU 2 } & \multicolumn{2}{c|}{ PU 3 } & \multicolumn{2}{c|}{ PU 4 } \\
\cline { 2 - 10 } & Dry & Wet & Dry & Wet & Dry & Wet & Dry & Wet \\
\hline Thermally & 129 & 135 & 125 & 130 & 116 & 115 & 110 & 100 \\
\hline 30 kGy & 128 & 133 & 123 & 128 & 114 & 110 & 108 & 95 \\
\hline $\mathbf{5 0}$ kGy & 123 & 129 & 118 & 124 & 110 & 98 & 102 & 93 \\
\hline $\mathbf{1 0 0}$ kGy & 120 & 126 & 115 & 120 & 106 & 93 & 95 & 90 \\
\hline $\mathbf{1 5 0}$ kGy & 110 & 120 & 100 & 115 & 89 & 90 & 77 & 88 \\
\hline
\end{tabular}

\section{Thermal stability}

The initial TGA thermograms of untreated and coated cotton/ PET fabrics with different PU-formulations, cured either thermally or by using of $\gamma$-rays (150 kGy) are shown in Fig. 5.

Fig. 6 illustrates the rate of thermal decomposition reaction $(\mathrm{dw} / \mathrm{dt})$ or the derivative of the thermogravimetric analysis curve (DTGA) taken from the initial TGA for cotton/ PET blend fabrics and it determines also, the Egypt. J. Rad. Sci. Applic., Vol. 27, No. 1-2 (2014) 
temperatures at maximum rate values of thermal decomposition reaction $\left(\mathrm{T}_{\max }\right)$, before and after coating with PU-formulations cured either thermally or with gamma irradiation. The wt losses of the tested fabrics at different temperatures are shown in Table 3. It must be noted that the thermal degradation of the uncoated blend fabrics bath through two degradation steps, represents the thermal degradation of cotton and polyester part of blend fabric. After coating with PU-formulations, three main pathways for the urethane linkage degradation beside the thermal degradation of blend fabrics: dissociation of primary amine, olefin and carbon dioxide; as well as the formation of secondary amine with elimination of carbon dioxide (Allen et al., 1999).

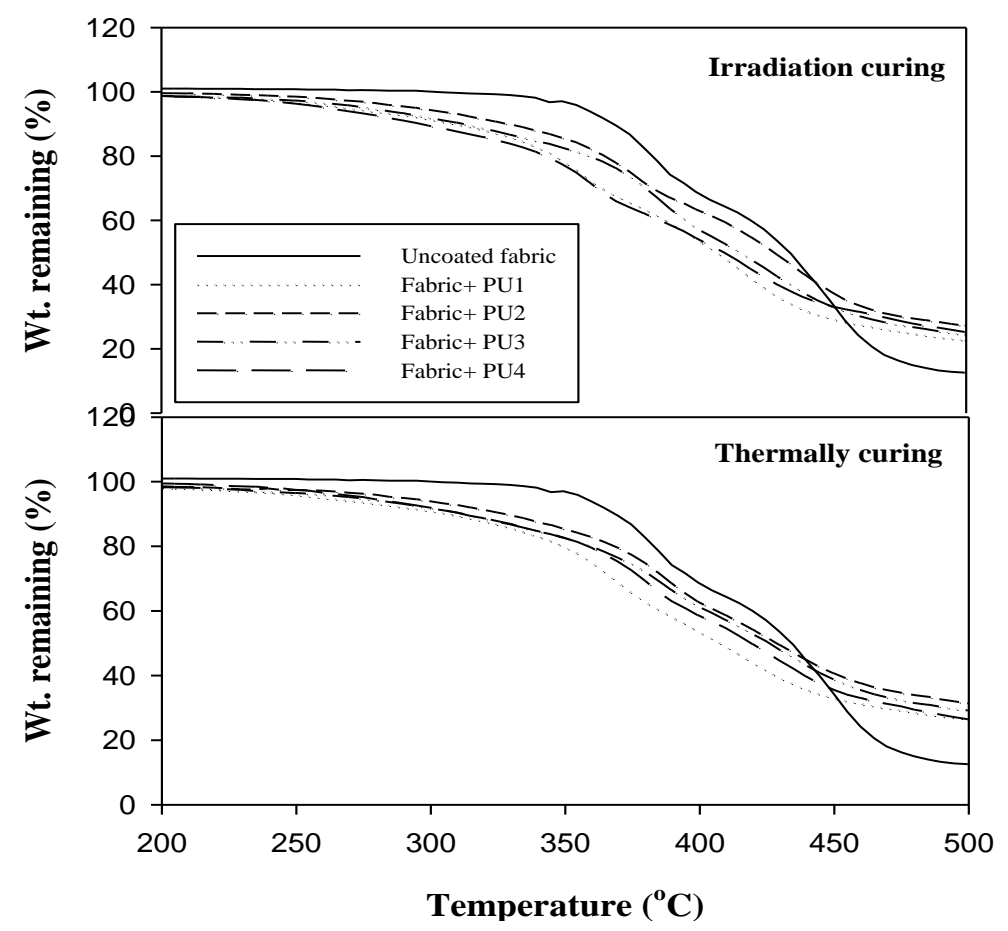

Fig. 5. The initial TGA thermograms of uncoated and coated cotton/ PET fabrics with different PU-formulations cured either thermally or with $\gamma$-rays.

From Fig . 5, 6 \&Table 3, it can be seen, in general, that the coated fabrics with PU-formulations has lower thermal stability in both of the 2 cases of curing. This could be attributed to the low thermal stability of coating PU film ingredients, which represent great mass fraction of the studied sample, which begin to dissociate firstly at lower degradation temperature than the uncoated fabrics.

Egypt. J. Rad. Sci. Applic., Vol. 27, No. 1-2 (2014) 


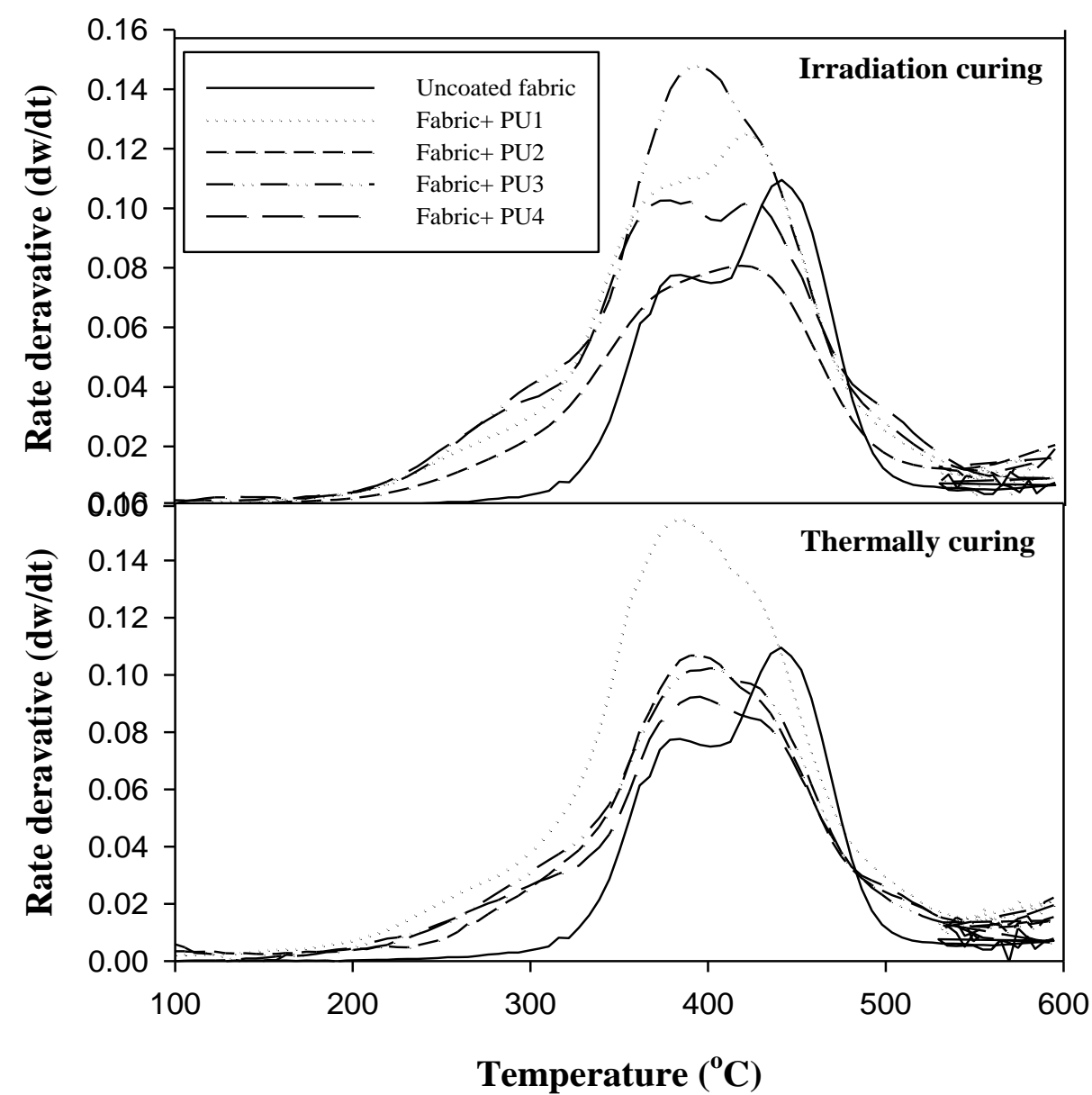

Fig. 6. The rate of thermal decomposition reaction of uncoated and coated cotton/ PET fabrics with different PU-formulations cured either thermally or with $\gamma$-rays.

The comparison between the 2 curing systems, it was found that the coated fabrics with different PU-formulations, cured by using $\gamma$-rays (150 kGy) have a higher thermal stability than the thermally cured fabrics. It was found also that, the thermal stability of coated fabrics with different PU formulations cured either thermally or with irradiation was affected by the $\mathrm{CE}$ percent in the PUformulations, in which it increases increasing the $\mathrm{CE}$ percent, due to the increasing in the urethane $\mathrm{H}$-bond density, as a result of the increasing of the aliphatic diols of $\mathrm{CE}$.

Egypt. J. Rad. Sci. Applic., Vol. 27, No. 1-2 (2014) 
TABLE 3. Thermal parameters of cotton/ PET blend fabrics coated with different PU formulations cured thermally or with $\gamma$-rays.

\begin{tabular}{|c|c|c|c|c|c|c|c|c|}
\hline \multirow{2}{*}{$\begin{array}{c}\text { PU } \\
\text { coating }\end{array}$} & \multirow{2}{*}{$\begin{array}{c}\text { Curing } \\
\text { condition }\end{array}$} & \multicolumn{6}{|c|}{ Wt loss (\%) } & \multirow{2}{*}{$\mathbf{T}_{\max }\left({ }^{\circ} \mathrm{C}\right)$} \\
\hline & & $250^{\circ} \mathrm{C}$ & $300^{\circ} \mathrm{C}$ & $350^{\circ} \mathrm{C}$ & $400^{\circ} \mathrm{C}$ & $500^{\circ} \mathrm{C}$ & $600^{\circ} \mathrm{C}$ & \\
\hline Non & $==$ & 0.0 & 0.154 & 2.92 & 33.59 & 87.43 & 92.25 & 441 \\
\hline PU 1 & \multirow{4}{*}{$\begin{array}{c}\gamma \text {-rays } \\
150 \mathrm{kGy}\end{array}$} & 2.28 & 6.72 & 15.49 & 38.57 & 75.89 & 80.89 & 426 \\
\hline PU 2 & & 2.74 & 6.88 & 15.80 & 38.98 & 73.21 & 79.83 & 423 \\
\hline PU 3 & & 3.00 & 8.86 & 18.63 & 42.43 & 72.58 & 79.14 & 395 \\
\hline PU 4 & & 3.61 & 8.93 & 19.00 & 43.45 & 71.29 & 78.59 & 427 \\
\hline PU 1 & \multirow{4}{*}{$\begin{array}{c}\text { thermally } \\
140{ }^{\circ} \mathrm{C} \\
5 \mathrm{~min}\end{array}$} & 3.43 & 7.99 & 16.92 & 41.96 & 72.64 & 78.35 & 389 \\
\hline PU 2 & & 3.83 & 8.70 & 17.86 & 39.28 & 69.19 & 75.64 & 398 \\
\hline PU 3 & & 3.92 & 8.92 & 18.37 & 38.55 & 69.00 & 74.90 & 400 \\
\hline PU 4 & & 4.00 & 9.08 & 18.80 & 38.22 & 68.90 & 74.00 & 403 \\
\hline
\end{tabular}

\section{Scanning electron microscope (SEM)}

SEM was used to demonstrate the structure morphology of cotton/ PET blend fabrics, before and after coating with formulation PU4, cured either thermally or by using $150 \mathrm{kGy}$ of $\gamma$-rays as shown in Fig. 7 .
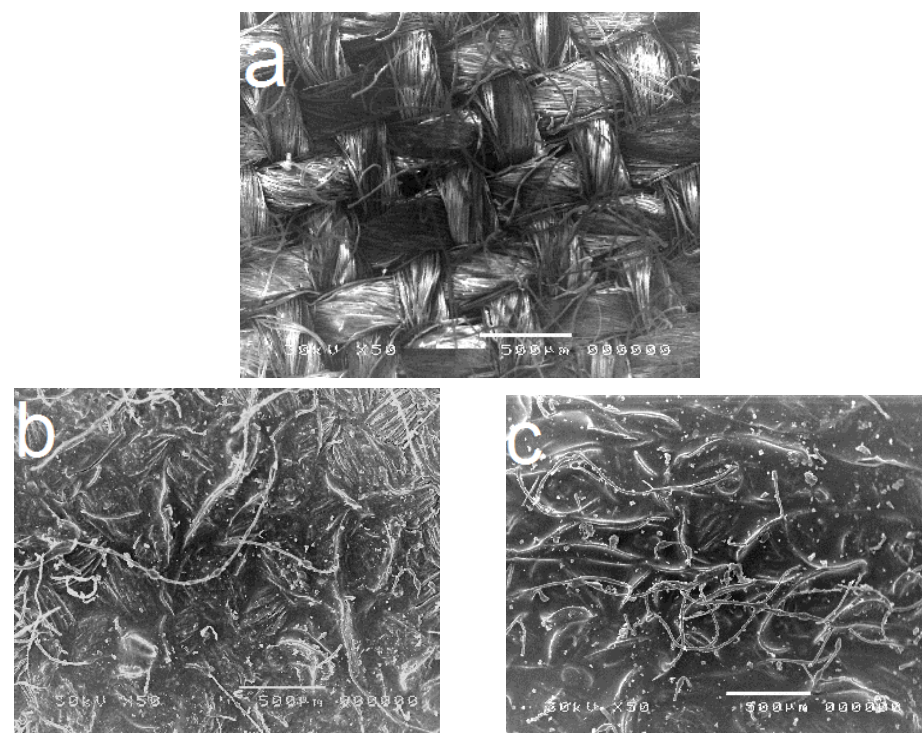

Fig. 7. The micrographs of (a) uncoated cotton/ PET blend fabric, (b) coated fabrics with PU4 formulation cured thermally and (c) cured at $150 \mathrm{kGy}$.

It was noticed clearly the weaving structure of cotton/ PET blend fabric, which filled with porous before any coating process as shown in Fig. 7(a). After coating with PU- formulation, the weaving structure of the fabric surface was filled with the PU-elastomerics layer, covering the fabric surface porous. The Egypt. J. Rad. Sci. Applic., Vol. 27, No. 1-2 (2014) 
same results were obtained for the coated fabrics cured thermally as shown in Fig. 7(b) or that cured at $150 \mathrm{kGy}$ of irradiation dose, as shown in Fig. 7(c). The covering of the fabric porous with PU-formulation can explain the improving in the water resistance properties of coated fabrics.

\section{Conclusion}

Different PU-formulation were prepared according to the CE percent and used as coating films up on the cotton/ PET blend fabrics. The coating PU films were cured thermally or by using $\gamma$-rays. By studying the effect of the coating process up on the fabric properties, such as mechanical properties, thermal stability, crease recovery and water absorbance, it can be concluded the following points: The $\gamma$-rays can be used successfully as a curing system for PU-formulation. The increasing of CE percent in the PU-formulations improves the mechanical properties, thermal stability of the coated fabrics. The prepared coated fabrics can be used successfully as water repellent fabrics, suitable for outdoor uses.

\section{References}

Allen, N. S., Edge, M. (1999) Fundamentals of polymer degradation and stabilization, Elsevier Applied Science, London, 1.

Barikani, M., Zia, K. M., Bhatti, I. A., Zuber, M. and Bhatti, H. N. (2008) Molecular engineering and properties of chitin based shape memory polyurethane elastomers. Carbohyd. Polym., 74, 621.

Boris, M., Helfried, H. and Horst, B. (2005) Functionalisation of textiles by inorganic sol-gel coatings. Mater. Chem., 15, 4385.

Chapiro, A. (1995) General consideration of the radiation chemistry of polymers. Nucl. Instrum. Meth. B, 105, 5 .

El-Naggar, A. M., Zohdy, M. H., Saied, H. M, El-Din, S. M., and Noval, D. M. (2005) Pigment colors printing on cotton fabrics by surface coating induced by electron beam and thermal curing. Appl. Surf. Sci., 241, 420.

Jong-Kook, Y., Hye-Jin, Y. and Han-Do, K. (2007) Preparation and properties of waterborne polyurethane-urea/sodium alginate blends for high water vapour permeable coating materials. Appl. Polym. Sci., 105, 1168.

K'rol, P., K'rol, B., Pikus, S. and Skrzypiec, K. (2005) Study on the synthesis and on super molecular structures of a water-dilutable urethane-acrylic copolymer applicable as a binder for powdered $\mathrm{Al}_{2} \mathrm{O}_{3}$. Colloid. Surface. A, 259, 35.

Egypt. J. Rad. Sci. Applic., Vol. 27, No. 1-2 (2014) 
Minghua, Y., Guotuan, Gu., Wei-Dong, M. and Feng-Ling, Q. (2007) Super hydrophobic cotton fabric coating based on a complex layer of silica nanoparticles and perfluorooctylated quaternary ammonium silane coupling agent. Appl. Surf. Sci., 253, 3669.

Oprea, St., Vlad, S. and Stanciu, A. (2000) Optimization of the synthesis of polyurethane acrylates with polyester compounds. Eur. Polym. J., 36, 2409.

Oprea, S. (2010) Dependence of fungal biodegradation of PEG/castor oil-based polyurethane elastomers on the hard-segment structure. Polym. Degrad. Stabil., 95, 2396.

Saad, M., Mohamed, K. and Mohamed, S. (2005) Electron-beam modification of textile fabrics for hydrophilic finishing. Appl. Surf. Sci., 241, 309.

Stéphane, G., Serge, B., Maryline, R., Isabelle, V., Lan, T., René. D. and Franck, P. (2005) Flame retarded polyurea with microencapsulated ammonium phosphate for textile coating. Polym. Degrad. Stabil., 88, 106.

Wang, F., Hu, J. Q. and Tu, W. P. (2008) Study on microstructure of UV-curable polyurethane acrylate films. Prog. Org. Coat., 62, 245.

Wilhelm, C., Rivation, A. and Gardette, L. (1998) Infrared analysis of the photochemical behaviour of segmented polyurethane:3.Aromatic diisocyanate based polymers. Polymer, 39, 1223.

Zia, K. M., Bhatti, H. N. and Bhatti, I. A. (2007) Methods for polyurethane and polyurethane composites, recycling and recovery: A review. React. Funct. Polym., 67, 675.

Zia, K. M., Bhatti, I. A., Barikani, M., Zuber, M. and Sheikh, M. A. (2009) Thermomechanical characteristics of UV-irradiated polyurethane Elastomers extended with $\alpha, \omega$-alkane diols. Nucl. Instrum. Meth. B, 267, 1811.

(Received: 16/12/2013;

accepted: 09/02/2014)

Egypt. J. Rad. Sci. Applic., Vol. 27, No. 1-2 (2014) 


\section{خصـائص أسـطح اقمشـة مخلـوط القطن/بـولي اسـتر المغطــاة

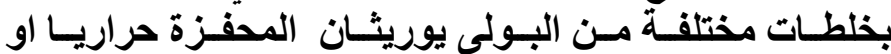 باستخدام اشعة جامات مخان حنان محمد عيسى و محمود صلاح الاين حسن

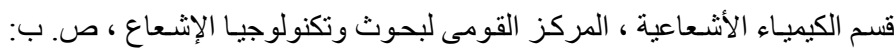

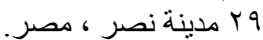

تم تحضير خلطات مختلفة من البولى يوريثان. و استخدامها لتغطية

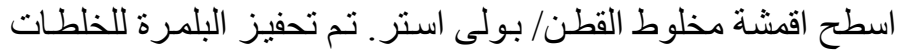

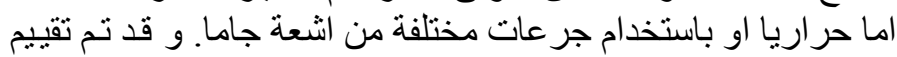

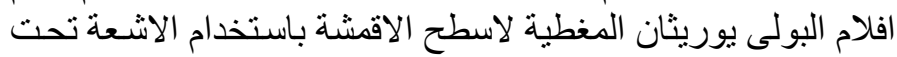

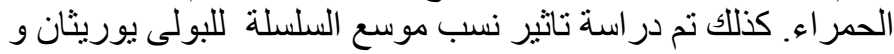

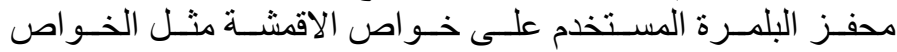

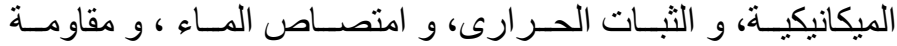

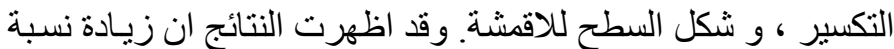

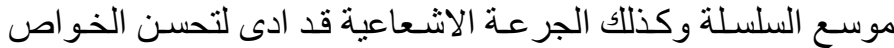

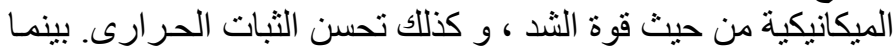

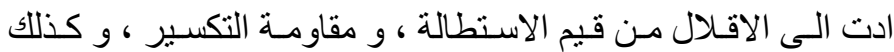

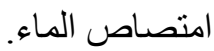

